\title{
TUBERCULOSIS AND LEPROSY.
}

\section{IMMUNOLOGICAL STUDIES.}

\author{
John Lowe, C.B.E., M.D., M.R.C.P., and F. McNulty
}

\section{INTRODUCTION.}

For the last twenty years and more, some leprosy workers havi: entertained the idea that persons who are immune to tuberculosis may show some degree of immunity to leprosy. Certain clinical, epidemiological and immunological findings pointed, rather vaguely it is true, to this conclusion. The advent of B.C.G. vaccination as a prophylactic measure in tuberculosis obviously added importance to this matter. Starting with the report of Fernandez (I) in I939, several workers have reported that B.C.G. vaccination converts not only a negative response to tuberculin into a positive one, but also a negative response to lepromin into a positive one in the same person. Moreover Fernandez (2) later reported that leprominnegative healthy persons could be made lepromin-positive by the injection of suspensions of the tubercle bacillus or the leprosy bacillus killed by heat. Most leprosy workers consider that a positive lepromin test indicates a degree of immunity to leprosy. Some such workers have therefore been strongly advocating the use of B.C.G. vaccination in persons, particularly young children of leprous parents, who are intimately exposed to leprous infection, and good results are already being reported from this measure.

The matter is obviously one of great interest and importance; a simple and reliable method of immunizing " contacts ' against leprosy might prove a very potent weapon in anti-leprosy work. Further, some workers, among whom Chaussinand (3) is prominent, consider that cross immunity between tuberculosis and leprosy is of great epidemiological importance. An article by Chaussinand on this subject is translated elsewhere in this issue.

So far the work on this subject has been done almost entirely by South American and French workers; a British contribution to the subject is overdue. In the present article, we attempt to review the available literature on the subject and to assess its value and significance, and at the same time to report on the early phases of a practical study of the subject, which aims at being as intensive and extensive as circumstances here in Nigeria permit.

In order to make the matter comprehensible to as many as possible, the history and development of knowledge of the im- 
munology of leprosy is briefly outlined. Cross immunity between tuberculosis and leprosy is of interest to many besides leprosy workers, and particularly to tuberculosis workers who may not be familiar with the main facts regarding the lepromin test.

\section{THE LEPROMIN TEST.}

The lepromin test constitutes the results of attempts over forty years to develop in leprosy work a test similar in nature to the tuberculin test in tuberculosis.

In leprosy, the bacilli cannot be cultivated, and experimental animals are not susceptible; therefore the only source of bacillary material is the lesions of patients suffering from leprosy. In leprous nodules, the bacilli are very numerous, counts as high as one thousand million per cubic centimetre of tissues having been recorded by Hanks (4). By excising such nodules, sterilizing by heat and by grinding them up in saline, vast numbers of bacilli are liberated, and suspensions of this nodular material can be made suitable for injection. Such suspensions contain not only bacilli but tissue cells fluids and lipoids, but the antigenic material is the bacilli.

According to Hayashi (5), K. Mitsuda (6 and 7) was the first to record that the intradermic injection of a small amount (o.I cc) of a boiled emulsion made from excised leprous nodules ground up, usually gave a positive response in healthy (adult) contacts, in noncontacts, and also in " maculo-anaesthetic " cases of leprosy, (these cases are often mild and self-limiting), and usually gave a negative response in cases of " nodular " type (usually severe and progressive).

The positive result however was peculiar, a definite small nodule developing slowly at 2 to 5 weeks and then slowly subsiding. Mitsuda interpreted this positive result seen in healthy people and in the mild self limiting forms of leprosy as indicating " resistance,' partial or complete, to leprous infection.

Numerous later workers confirmed all these main points, and also added further information. In young healthy children, the result was usually negative, but with increasing age often became positive. The frequent occurrence of positive results in healthy adults, even in countries where there was no leprosy, was confirmed. The test, often known as the Mitsuda test, became a routine procedure, not in diagnosis of leprosy, for here it was of practically no value, but in classification of cases and in prognosis.

The anomalous features of the test (a) the lateness of the reaction, (b) the positive results in persons with no contact with leprosy, and (c) the negative results in "nodular" (now called 
"lepromatous") cases, remained unexplained or only partly explained, though numerous writers suggested as the explanation of (b) infection with other acid-fast organisms, the tubercle bacillus being possibly one or the chief of these, and of (c) a specific anergy to the leprosy bacillus. This anergy is the most specific feature of the test.

The Nature of The POSitive Response to LePROMIN.

In brief, three different theories have been held by different workers. A few [e.g. Bargehr (8), Rotberg (9)] have considered a positive test as being caused by specific allergy to the leprosy bacillus and its products of disintegration. This view is no longer tenable and this position now seems to have no supporters. Rotberg himself has changed his mind on this matter.

Others have considered a positive reaction to be neither allergic nor specific, and have thought that a positive reaction was due to "resistance" of the body tissues to the bacilli, and that a negative reaction was due to lack of this " resistance." (The meaning of this term resistance was never clearly defined.) This position seems to have been undermined by more recent work reviewed later.

Most workers have regarded the positive reaction as allergic, but not specific in nature.

The work of Fernandez, and of Dharmendra has cleared up some anomalies. Fernandez (IO and II) showed that a positive late response (2-5 weeks) was almost always preceded by a " tuberculin-like" early response at $24-48$ hours, consisting of a definite area of erythema and oedema surrounding the point of injection. Others, e.g. Lowe and Dharmendra (I2), soon confirmed this, and these workers also showed that, by grinding the bacilli for several hours till the bacillary forms were few or no longer found, and by suspending in saline and injecting the residue, the early response was greatly increased and the late response was much diminished. They interpreted these findings as indicating, that (a) both the early (Fernandez) and the late (Mitsuda) reaction to injection of lepromin were allergic in nature, and moreover (b) that they were both due to the same antigen, the early reaction being due to free antigen present in the lepromin, and the late reaction due to slow liberation of the same antigen from the bacilli by slow disintegration at the site of injection. The findings were supported by histological studies. Fernandez however interpreted his findings as indicating two antigens, one active at 24-48 hours and the other at 2-5 weeks.

Wade (I3) expressed still another view of the mechanism of the late reaction. He thought that the test might not reveal the presence of allergy at the time of the injection of lepromin, but only 
of potential allergy. In persons who were only potentially allergic, when lepromin was injected, the allergy induced by the injection showed itself 2-5 weeks later by reaction at the site of the injection, where bacilli are still present. Persons who were not even potentially allergic showed no such reaction.

[There is one serious difficulty presented by Wade's theories. If they were true, persons who had never been exposed to leprous infection, and could therefore be only potentially allergic, should show no early reaction but only the late one. Various workers have reported that this is not so; it appears that even in a person never exposed to leprous infection, a positive late reaction is usually preceded by an early (24-48 hours) reaction. Wade himself (I4) realised and discussed this difficulty.]

Ideas rather similar to those of Wade in certain respects have been expressed by other workers, several having considered that some inherent constitutional factor influenced the results of the lepromin test. For example, Rotberg (9) thought that many people, probably the big majority, were potentially allergic to the leprosy bacillus, and that when infected with leprosy, they developed either no disease or else the mild " maculo-anaesthetic" form these being the lepromin-positive persons; on the other hand some, probably a minority, were inherently incapable of reacting allergically to lepromin or to leprous infection, and, if infected with leprosy, they developed the severe " nodular" or lepromatous form of the disease, the lepromin test remaining of course negative.

These ideas, if true, would have an important bearing on the question of the possibility of immunization against leprosy; they are discussed in that connection later.

There still seems to be no unanimity among leprosy workers regarding the nature and mechanism of the reaction to lepromin. All these three views however (those of Fernandez, of Lowe and Dharmendra, and of Wade) accept allergy as the basis of the reaction. We have seen no reason to abandon the view expressed by Lowe and Dharmendra that one antigen only operates, and Dharmendra's later work supports that view, for he (I5) developed a method of completely separating leprosy bacilli from leprous tissue and preparing lepromin which could be standardized by weight, and moreover he (I6) was able to isolate various chemical fractions of such isolated bacilli. $\mathrm{He}$ isolated soluble antigenic fractions (protein) from the bacillus which give a marked early reaction and no late reaction; he failed to isolate any fraction which gave a late reaction only.

Regarding specificity; the positive findings in people never exposed to leprous infection have already been mentioned and are 
discussed more fully later. Dharmendra and Jaikaria (I7) failed to find any fraction of the leprosy bacillus which when injected gave a response which was specific for leprous infection. They and others considered infection with the tubercle bacillus as a possible or probable cause of non-specific response to the injection of lepromin. Recent work, more fully discussed later, supports this idea.

This then is the present position of the lepromin test. It is regarded as allergic but non-specific, of value mainly in classification and prognosis. The injection of lepromin can produce two responses, an early $(24-48$

phenomenon) and a late (2-5 weeks) response of nodular type (the Mitsuda phenomenon); both these responses have, in the opinions of some workers, the same significance, although some other workers think that the early response indicates " sensitivity " and the late response indicates immunity. The grounds for this differentiation are not clear and it is not possible here to discuss this matter further. (In the present study both readings have been made, but the late reading alone is considered here. The two have usually agreed.)

\section{VARIATIONS IN RESULTS OF THE LEPROMIN TEST.}

It is advisable here to consider the question whether the results of the lepromin test in any individual can vary from natural causes. That lepromin-negative healthy persons can become leprominpositive as the result of exposure to infection with leprosy bacilli is generally recognized, and most workers consider that infection with other acid-fast bacilli, particularly the tubercle bacillus, can produce the same result. This matter is discussed more fully later.

In persons with leprosy of the lepromatous type (lepromin negative) a few workers have reported that when the disease subsides under chemotherapy, the lepromin test may become positive. Such reports are few. We, personally, in an experience of several hundreds of such cases over six years, have not been able to demonstrate this change in a single case.

Regarding the possibility of lepromin-positive persons becoming lepromin-negative, opinion seems to be divided. Regarding nonleprous but lepromin-positive persons, information is scanty. Regarding persons with leprosy, a few workers have reported that lepromin-positive " maculo-anaesthetic " or " tuberculoid " cases can develop into lepromin-negative " lepromatous" cases, but even such workers do not find that this change is common; most workers find that while the degree of positivity in the lepromin test may vary at different times with varying phases of activity and quiescence of this (allergic) tuberculoid form of the disease, a change from frank lepromin positive to complete negative, and a corresponding change 
in the type of the leprosy, appears extremely rare or, in the opinion of some, impossible.

Thus, on the whole, the allergic response seen in the lepromin test in some persons (presumably the result of exposure to infection with acid-fast bacilli) is very persistent; similarly the lack of response of other persons not only exposed to such infections but actually suffering from lepromatous leprosy, is also very persistent.

These findings tend to support the idea of an inherent factor influencing the results of the lepromin test.

THE RELATION BETWEEN THE LEPROMIN RESPONSE AND THE FORM OF THE DISEASE.

Finally the following question must be considered. In cases of leprosy, is it the form and the severity of the disease which determines the response seen in the lepromin test, or is it the reverse, namely is it the allergy or immunity of the body, as demonstrated by the lepromin test, which determines the form of the disease?

While a few workers seem to have adopted the first view, most appear to adopt the second, which is much more easily reconciled with the known facts, for example, that persons with no leprosy and never exposed to leprous infection are often lepromin-positive; that once a person is found positive or negative he almost always remains so; that subsided lepromatous cases nearly always remain leprominnegative, and so on.

Thus the two main forms of leprosy, the allergic (tuberculoid) form, and the anergic (lepromatous) form, appear to represent two widely differing ways in which the body may react to leprous infection, the form of the disease being determined by the state of the body (sensitization, allergy and possibly immunity) existing at the time of infection or developing early in response to that infection, this allergy usually persisting indefinitely.

The important question whether a positive lepromin test indicates immunity to leprosy is discussed later.

\section{THE TUBeRCULIN TEST.}

In almost every way this test and the significance of its results are very much simpler and easier to discuss than the lepromin test and its results. There is almost universal agreement that a positive result is an allergic phenomenon which indicates sensitization to the tubercle bacillus and its products introduced into the body in the form of a natural infection or by the procedure of B.C.G. vaccination.

It is however true that a few workers have at times questioned its specificity. For example, Cummins and Leroux (18), finding 
rather an inexplicably high tuberculin-positive rate in one part of Africa, considered and investigated the possibility of some of the positive results being due to leprous infection patent or otherwise, but with negative results. Chaussinand (3) in a recent discussion of the subject does not state definitely that leprosy can cause a positive tuberculin test, but he does state that patients with tuberculoid (allergic) leprosy, free from tuberculous infection, react strongly to the intradermal injection of Koch's bacillus killed by heat, while healthy people and people with lepromatous (anergic) leprosy show no such reaction.

On the whole, the specificity of the tuberculin test remains without serious challenge. A positive result indicates tuberculous infection past or present. A negative result however does not necessarily indicate the absence of such infection. Even in severe tuberculous disease, such as miliary tuberculosis and the last stages of pulmonary tuberculosis, the tuberculin test may be negative, indicating an anergy (which recalls in some respects the anergy of lepromatous leprosy).

One further point about the tuberculin test should be mentioned. It is apparently not unusual for the result of the test to be found changing from positive to negative and vice versa. It has been suggested that the test remains positive only in the presence of infection, which is often, however, latent and inactive. After complete eradication of tuberculous infection a positive tuberculin test may slowly become negative; with reinfection it may become positive again. Further, with progressive spread of the disease, a person previously positive may become negative.

Similar findings are recorded after B.C.G. vaccination. The positive tuberculin test induced by this measure is often short-lived, and to maintain positively repeated vaccination is often necessary.

These findings contrast with the persistence of the response in the lepromin test.

\section{METHODS OF TUBERCULIN AND LEPROMIN TESTING USED.}

The best general method of making lepromin is believed to be that of Dharmendra (I5); by this method a lepromin is prepared consisting of leprosy bacilli and nothing else; thus it can be standardized by weight. This method involves centrifugalizing in ether at a temperature not too high. The use of this method here in Eastern Nigeria was rendered difficult by the high temperature and the lack of refrigerators large enough to contain an electric centrifuge, though one lot of lepromin was prepared in this way. This lot was used as a standard. Further lots of lepromin were prepared by the following method. Excised nodules were sterilized in an autoclave and 
ground in chloroform by Dharmendra's method till nearly all the bacilli had been extracted. The chloroform (containing the bacilli and the tissue lipoids) was evaporated on a hot water bath. The residue was very fatty; it was suspended in saline by grinding in a pestle and mortar. The result was a saline suspension of leprosy bacilli with also many fat globules. The suspension was allowed to stand and the fat globules coalesced; it was then filtered twice through fine filter paper, which removed most of the fat, leaving a fine suspension of leprosy bacilli; .5\% carbolic was added.

This lepromin was standardized against the lepromin already standardized by weight prepared by the method of Dharmendra, dilutions from $I$ in 5 to $I$ in 20 being prepared and o.I c.c. being injected intradermally into patients with leprosy of the two main types, allergic and anergic; at the same time o.I c.c. of the standard preparation was injected. The dilution which gave the same results as the standard lepromin was adopted for routine use. The undiluted lepromin was stored, and some was diluted with normal saline on each day on which the test was used.

This lepromin has proved very satisfactory, and is maintaining its potency very well. The early (24-48 hours) response in our dark skinned Africans is often not easy to read with accuracy; but a definite early response has always been followed by a marked late (2-5 weeks) response. The late response has been the one used here in recording the patient as positive, doubtful, or negative.

In deciding what is positive the following criteria have been adopted. A positive result means a definite nodule easily palpable and usually easily visible, detectable in the third and fourth weeks. " Pin head " nodules have been ignored in this work. The nodules recorded as positive have measured $4 \mathrm{~mm}$. to Io $\mathrm{mm}$. or more in diameter, the large ones often showing superficial alteration.

In a few cases only, the results have been recorded as doubtful.

The tuberculin used in this work was obtained from the Pasteur Institute, Paris. In all cases, a preliminary scratch test (cuti reaction) was done with crude tuberculin undiluted, the readings being made at 48 and 72 hours; if a definite reaction was obtained, no further test was done. Patients with doubtful and negative results were then given an intradermal injection of 50 international units of purified tuberculin. In practice, a definite raised area of erythema and oedema measuring eight or more millimetres in diameter was recorded as positive, though the nature of the reaction rather than the measurement was the deciding factor in a few doubtful cases. (In some doubtful cases a further test with I in roo tuberculin was done, but these results are not here recorded.) 


\section{A. STUDIES IN HEALTHY PERSONS.}

Several studies of a nature similar to the present one have been made in the past and are discussed later. The issues can easily be confused by the presence of leprosy.or of tuberculosis in the persons studied. A study made in healthy persons is in many ways far more illuminating.

FINDINGS OF THE PRESENT STUDY.

We have made the following studies of the results of the lepromin and tuberculin tests in healthy Africans here in Uzuakoli. Nigeria.

(a) Studies in childien ages 1-15.

No. tested 8r.

Tuberculin positive $47(58 \%)$

Lepromin positive 3 I $(35 \%)$

From the above data it is possible by simple calculation to find out the proportion of the cases in which the results of the two tests should agree or should disagree, and in what way they should agree and disagree, if the two tests are entirely independent.*

The figures are here given, together with the actual findings made:

\begin{tabular}{|c|c|c|c|c|c|}
\hline $\begin{array}{l}\text { Expected } \\
\text { Actual }\end{array}$ & $\begin{array}{c}\text { Both tests } \\
\text { positive } \\
22 \% \\
\text { (3r) } 38 \%\end{array}$ & $\begin{array}{c}\text { Both tests } \\
\text { negative } \\
26 \% \\
\text { (34) if } 2 \%\end{array}$ & $\begin{array}{c}\text { Tuberculin } \\
\text { positive } \\
\text { Lepromin } \\
\text { negative } \\
36 \% \\
\text { (I6) } 20 \%\end{array}$ & $\begin{array}{l}\text { Tuberculin } \\
\text { negative } \\
\text { Lepromin } \\
\text { pasitive } \\
\text { r6\% } \\
\text { nil }\end{array}$ & $\begin{array}{l}\text { Lisagree- } \\
\text { ment }\end{array}$ \\
\hline
\end{tabular}

It will be seen that the actual results obtained were very different from those expected if the two tests are entirely independent. Moreover, these differences when examined statistically (this has been done for us by Dr. B. Nicholson) are highly significant. The two tests are not independent; the results of the two tests agree far more often than they should do if they are independent.

* This simple calculation can best be explained by an example. A reasonable sized group of persons is tested, say 200. The following findings are made.

Tuberculin positive $60 \%$, negative $40 \%$

Lepromin positive $55 \%$, negative $45 \%$

If the two tests are independent, the one test having no influence on the other, the grouping of the 200 patients should be

Tuberculin and lepromin positive $\quad 55 \%$ of $60 \%=33 \%$ ) $5 \mathrm{I} \%$

Tuberculin and lepromin negative $\quad 45 \%$ of $40 \%=18 \%$ agreement

Tuberculin positive and lepromin negative $45 \%$ of $60 \%=27 \% \quad 79 \%$ Tuberculin negative and lepromin positive $55 \%$ of $40 \%=22 \%$ disagree- 
(b) Studies in adults.

No. tested 278 .

Tuberculin positive $223(80.2 \%)$

Lepromin positive $224(80.5 \%)$

A study of the results by the methods outlined above gives the following results:-

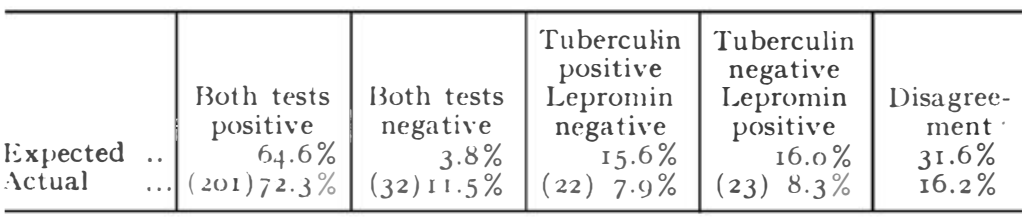

In this group of adults, with both tuberculin and lepromin positive rates considerably higher than in children, the findings are less striking, and the differences between the results calculated on the basis of the two tests being independent and the actual results observed are less marked than in the children; nevertheless the differences are of the same nature, and moreover, statistical analysis shows that they are significant, and that there is a greater agreement between the results of the two tests than can possibly occur by hance.

\section{Discussion.}

We now look at the figures of similar studies made by other workers in other countries and analyse them in the same way.

Dharmendra and Jaikaria (I9) studied 260 healthy persons in the Punjab (India) where there was practically no leprosy and not much tuberculosis and gave the following figures:

260 tested. Tuberculin positive $52 \%$

$$
\text { Lepromin positive } 35.4 \%
$$

\begin{tabular}{|c|c|c|c|c|c|}
\hline & $\begin{array}{c}\text { Both tests } \\
\text { positive }\end{array}$ & $\begin{array}{c}\text { Both tests } \\
\text { negative }\end{array}$ & $\begin{array}{l}\text { Tuberculin } \\
\text { positive } \\
\text { Lepromin } \\
\text { negative }\end{array}$ & $\begin{array}{c}\text { Tuberculin } \\
\text { negative } \\
\text { Lepromin } \\
\text { positive }\end{array}$ & $\begin{array}{c}\text { Disagree- } \\
\text { ment }\end{array}$ \\
\hline $\begin{array}{l}\text { Expected } \\
\text { Actual }\end{array}$ & $\begin{array}{l}18.4 \% \\
28.0 \%\end{array}$ & $\begin{array}{l}31.0 \% \\
+0.4 \%\end{array}$ & $\begin{array}{l}33.6 \% \\
24.2 \%\end{array}$ & $\begin{array}{r}17.0 \% \\
7.3 \%\end{array}$ & $\begin{array}{l}50.6 \% \\
3 \mathrm{I} .5 \%\end{array}$ \\
\hline
\end{tabular}

These results again show the same thing, but since the tuberculin-positive and lepromin-positive rates are lower than here in Nigeria, the differences are in some respects more marked.

The same general findings are also found in the report of Chaussinand (20) from Indo-China, where both leprosy and tuberculosis are common.

Cases tested 23I (children 4-8 years). Tuberculin positive 
$61.4 \%$; lepromin positive $65.4 \%$ :

\begin{tabular}{|c|c|c|c|c|c|}
\hline $\begin{array}{l}\text { Expected } \\
\text { Actual }\end{array}$ & $\begin{array}{c}\text { Both tests } \\
\text { positive } \\
40.1 \% \\
54.1 \%\end{array}$ & $\begin{array}{c}\text { Both tests } \\
\text { negative } \\
13.4 \% \\
29.3 \%\end{array}$ & $\begin{array}{l}\text { Tuberculin } \\
\text { positive } \\
\text { Lepromin } \\
\text { negative } \\
21.2 \% \\
7.4 \%\end{array}$ & $\begin{array}{l}\text { Tuberculin } \\
\text { negative } \\
\text { Lepromin } \\
\text { positive } \\
25.3 \% \\
\text { I. } 1.2 \%\end{array}$ & $\begin{array}{c}\text { Disagree- } \\
\text { ment } \\
46.5 \% \\
18.6 \%\end{array}$ \\
\hline
\end{tabular}

Chaussinand's (3) report of studies of $4 \mathrm{I}$ children in Paris are also interesting when studied in the same way. (Three with " doubtful " results are omitted from this analysis.)

Persons tested 38 (children IO-I7 years). Tuberculin positive $44.7 \%$. Lepromin positive $47 \cdot 3 \%$.

\begin{tabular}{|c|c|c|c|c|c|}
\hline $\begin{array}{l}\text { Expected } \\
\text { Actual }\end{array}$ & $\begin{array}{c}\text { Both tests } \\
\text { positive } \\
21.1 \% \\
47.7 \%\end{array}$ & $\begin{array}{l}\text { Both tests } \\
\text { negative } \\
29.1 \% \\
52.6 \%\end{array}$ & $\begin{array}{l}\text { Tuberculin } \\
\text { positive } \\
\text { Lepromin } \\
\text { negative. } \\
23.6 \% \\
\text { nil }\end{array}$ & $\begin{array}{c}\text { Tuberculin } \\
\text { negative } \\
\text { Lepromin } \\
\text { positive } \\
26.2 \% \\
2.6 \%\end{array}$ & $\begin{array}{c}\text { 1) isagree- } \\
\text { ment } \\
49.8 \% \\
2.6 \%\end{array}$ \\
\hline
\end{tabular}

Although the group is small, the findings in Paris, where leprous infection is so rare, are very striking, and the results are undoubtedlysignificant.

\section{Conclusions.}

These three studies, our present study and the previous studies of Dharmendra and Jaikaria, and of Chaussinand, these studies having been made in different countries by different workers at different times, the methods used also differing, all point to the same conclusions; the two tests are not independent, and there is some factor operating strongly to make the two tests agree. What is this factor?

\section{THE CAUSE OF AGR EEMENT BETWEEN THE TWO TESTS.}

Four possibilities have to be considered.

Firstly, exposure to leprous infection (in this country leprosy is highly endemic, and many if not most of the persons tested have had contact with leprosy cases) might have made persons allergic to both the leprosy and the tubercle bacillus.

If this hypothesis were true, patients with leprosy of the allergic (tuberculoid) type should be tuberculin positive. As is seen later, this is often not so. There is practically no evidence to support this hypothesis; nearly all the evidence is against it.

Secondly, it might be postulated that persons had been exposed either to both infections or else to neither, although it would not be easy to explain how this might occur, in Nigeria at any rate. But this argument is upset by the fact that in persons never exposed to 
leprous infection and living in countries with no leprosy, the two tests agree in a still higher proportion of cases. This is shown in the reports of Chaussinand (3) and of Fernande' (I) on studies in Paris.

Thirdly, it might be postulated that some other factor, possibly some other acid-fast infection, is making people allergic to both the tubercle bacillus and the leprosy bacillus. This is perhaps less improbable than it might appear. Acid-fast bacilli are very common in nature, and can be found, isolated and cultivated from many natural sources. Very few of them are known to be pathogenic to man, but that does not mean that they could not infect man, and perhaps produce in man the power to react allergically to themselves and to other acid-fast bacilli, including the tubercle bacillus and the leprosy bacillus. Nevertheless there is no direct evidence to support this hypothesis.

Fourthly, much the most likely explanation is that exposure to tuberculous infection is making people allergic to the leprosy bacillus.

On this basis it is easy to explain how most healthy persons in most countries are allergic to both bacilli or to neither. In West Africa however and in other countries with much leprosy, it is more than possible that some persons have been exposed to leprous infection but not to tuberculous infection, and this would explain those cases which are lepromin-positive but tuberculin-negative. There remain however the cases that are tuberculin-positive but leprominnegative. Analysis of the 38 such cases in our present series shows that nearly all of them are weakly positive to tuberculin, which suggests that the degree of reaction to tuberculin influences the response to lepromin. Further examination of our records supports this view. In our 278 healthy adults studied, 7 I showed a definite reaction in the scratch test (cuti reaction) which indicates a high degree of sensitization to tuberculin, and $70(98.6 \%)$ of these showed a positive lepromin test, nearly all strongly positive. (One of these was in a person who had just left by air, and for the first time, a country with no leprosy.)

The observations recorded and quoted afford strong evidence that exposure to tuberculous infection, as shown by a positive tuberculin test, can, and usually does cause the lepromin test to become positive. In fact the observations can only be reasonably explained on this basis; no other hypothesis appears able to explain the facts.

This hypothesis is strongly supported by published work other than that already quoted.

The following workers have reported a high incidence of positive lepromin tests in adults in countries where there is little 
or no leprosy, and where the possibility of the positive results being due to leprosy can be ignored. Cummins and Williams (2I) in England, Dubois (22) in Belgium, Boncinelli (23) in Italy, Fernandez (I) in Paris, Convit Azulay et al. (24) in New York, Azulay and Convit in Ohio (25), Bechelli et al. (26) in New York, Dharmendra and Jaikaria (I9) in the Punjab, India, and Chaussinand (3) in Paris. Several of these workers have reported on the fact that tuberculin-positive persons studied were usually leprominpositive.

Other reports are those of Fernandez (I) who stated that in tested persons from countries with no leprosy, the agreement between the tuberculin and lepromin tests was $95 \%$, and of de Sousa Campos et al. (27) in Brazil, who found all Mantoux-positive isolated children of parents with leprosy studied were also leprominpositive (although some were lepromin-positive and Mantouxnegative). Garcia Miranda (28) in Cuba reported that, of nonleprous persons, $78 \%$ were lepromin-positive, and the results of the Mantoux tuberculin test and lepromin tests coincided.

Doubtless many other reports could be traced and quoted. The literature of the subject gives ample evidence to support the idea that tuberculous infection, as shown by a positive tuberculin test, can and usually does make the lepromin test positive. The present report only confirms the reports of previous workers.

There are however some reports of other workers who have studied the matter, which are rather less definite in their findings. Such reports include those of Rotberg and Bechelli (29), and of Convit, Azulay et al. (24) based on work in New York; although a later report of Azulay and Convit (25), based on work in Ohio, records a more definite correlation between the results of the two tests.

A very discordant note is struck by Radna (30), who in an area without much leprosy found that of 100 tuberculin-negative (cuti reaction) persons, 94\% were lepromin-positive. Such a report, quite unsupported by other workers, makes one doubt the efficiency of the methods used.

\section{THE EFFECT OF B.C.G. VACCINATION ON THE LEPROMIN AND TUBERCULIN TESTS IN HEALTHY PERSONS.}

The following published reports on this matter are a vailable. Fernandez (I) reported that, in persons negative to both tests, B.C.G. vaccination usually made both tests positive. He studied I22 children with no contact with leprosy or tuberculosis, all being lepromin- and tuberculin-negative. After B.C.G. vaccination, $99 \%$ became tuberculin-positive and $95 \%$ became lepromin-positive. 
Neyra Ramirez (3I) took 53 healthy persons negative in both tests, and gave B.C.G.; 87 became lepromin-positive.

Chaussinand (3) took 30 children negative in both tests, and found that all became lepromin-positive after B.C.G. vaccination.

Azulay (32) gave B.C.G. to I5 lepromin- and tuberculinnegative children. Twelve became tuberculin- and leprominpositive.

Gines and Poletti (33) studied 3I healthy children of leprous parents, giving B.C.G. vaccine. Twenty-five were found leprominpositive after vaccinátion. Of II whose previous lepromin test was not done, 9 were found positive, and of 20 whose previous test was negative, I6 became positive.

Rosemberg, de Souza Campos and Aun give two reports (34 and 35). In the first they studied 39 healthy children of leprous parents, all tuberculin- and lepromin-negative. In 27, B.C.G. was given daily and orally for 28 days in increasing doses, with a total dose of I.I9 G.* In all 27 , the lepromin test became positive; the tuberculin test became positive in 24 and doubtful in 3 . In the other 12 children, only one dose of B.C.G. (.I G.) was given. Nine became tuberculin-positive and 8 became lepromin-positive; 3 remained tuberculin- and lepromin-negative. In the second paper they studied 36 healthy tuberculin-negative children of healthy parents. B.C.G. was given orally for 28 days. This B.C.G. vaccine produced tuberculin conversions in 25 . Ten months later, 24 of the 25 had become tuberculin negative; the lepromin test was still found positive in all the 36 . Thus the lepromin test had become and remained positive after B.C.G. vaccination (a) in the I case becoming and remaining tuberculin-positive (b) in the 24 becoming tuberculin-positive but later reverting to negative and (c) in II who had never even become temporarily tuberculin-positive.

*In Brazil, where this work was done, the routine method of giving B.C.G. in the field is by the oral route. The dose used is now $100 \mathrm{~m} . \mathrm{g}$. in a single dose. This dose is large but is tolerated extremely well. Moreover this method has one great advantage in field work, that no preliminary tuberculin testing is necessary; persons who are strongly tuberculin-positive can take $100 \mathrm{~m} . \mathrm{g}$. of B.C.G. orally with no upset whatever. The extra cost of the large dose of B.C.G. is more than neutralized by the saving in time, staff, and work caused by the elimination of the preliminary testing.

For research purposes, and where statistics of the conversion rates are needed, this oral method of administration without preliminary testing is of course useless, except in children within a few weeks of birth, when it can safely be presumed that tuberculin and lepromin tests will be negative.

For field work on a large scale, this method has obviously great advantages. A study of its use in the mass B.C.G. campaigns now in progress in several countries would appear well worth while. At present, lyophilized B.C.G. in this dosage is not available. In Brazil they make their own B.C.G. in this dosage in liquid form, and it has to be used within 25 days. There appears no reason why doses of $100 \mathrm{~m} . \mathrm{g}$. should not be lyophilized to keep up to one year. If this could be done, the wide use of B.C.G. might be greatly facilitated. 
Their findings therefore indicated that by B.C.G. vaccine given orally, conversions from lepromin-negative to lepromin-positive were more common and also much more persistent than the tuberculin conversions produced by the same vaccination.

Other reports on the action of B.C.G. in converting a lepromin test from negative to positive include those of Rudianski (36) and Dauden Valls et al. (37).

PRESENT WORK.

B.C.G. vaccine has been given by intradermal injection of o. I m.g. in 63 healthy persons all of whom were tuberculin-negative, and all but seven lepromin-negative before the B.C.G. was given. The tuberculin and lepromin tests were repeated 2-3 months later.

(a) Very young babies-13.

B.C.G. given soon after birth. (No preliminary tuberculin and lepromin tests done, presumed negative.)

Tuberculin positive and lepromin positive Before B.C.G. After B.C.G. Tuberculin positive and lepromin doubtful Tuberculin positive and lepromin negative Tuberculin negative and lepromin positive Tuberculin negative and lepromin negative

$\begin{array}{ccc}\text { nil } & - & 9 \\ \text { nil } & - & 4 \\ \text { nil } & - & \text { nil } \\ \text { nil } & - & \text { nil } \\ \text { I3 } & - & \text { nil } \\ - & & - \\ \text { I3 } & & \text { I3 }\end{array}$

(b) Older babies-8.

Tuberculin positive and lepromin positive Before B.C.G. After B.C.G. Tuberculin positive and lepromin doubtful Tuberculin positive and lepromin negative Tuberculin negative and lepromin positive Tuberculin negative and lepromin negative

\begin{tabular}{lrrr}
\multicolumn{5}{c}{ Before B.C.G. } & After B.C. \\
ositive & nil & - & 3 \\
ubtful & nil & - & 4 \\
gative & nil & - & nil \\
ositive & nil & - & nil \\
gative & 8 & - & I \\
& - & & - \\
Total & 8 & & 8
\end{tabular}

(c) Older cbildren-29.

Tuberculin positive and lepromin positive Tuberculin positive and lepromin doubtful Tuberculin positive and lepromin negative Tuberculin negative and lepromin positive

Before B.C.G. After B.C.G. Tuberculin negative and lepromin negative

$\begin{array}{rrr}\text { nil } & - & 20 \\ \text { nil } & - & 6 \\ \text { nil } & - & 3 \\ \text { nil } & - & \text { nil } \\ 29 & - & \text { nil } \\ - & & - \\ 29 & & 29\end{array}$


Adults-15. Before B.C.G. After B.C.G.

Tuberculin positive and lepromin positive nil - I5

Tuberculin positive and lepromin doubtful nil _. nil

Tuberculin positive and lepromin negative nil - nil

Tuberculin negative and lepromin positive $\quad 7 \quad \ldots \quad$ nil

Tuberculin negative and lepromin negative $\quad 8 \quad \ldots \quad$ nil

$\begin{array}{lll}\text { Total } & \text { I5 } & \text { I5 }\end{array}$

Totals 65.

Before B.C.G. After B.C.G.

Tuberculin positive and lepromin positive

Tuberculin positive and lepromin doubtful

Tuberculin positive and lepromin negative

$\begin{array}{rrr}\text { nil } & - & 47 \\ \text { nil } & - & \text { I4 } \\ \text { nil } & - & 3 \\ 7 & - & \text { nil } \\ 58 & - & \text { I } \\ - & & - \\ 65 & & 65\end{array}$

\section{Conversions.}

Of 65 previously tuberculin-negative, 64 became positive

Of 58 previously lepromin-negative, 40 became positive

and I4 more became doubtful

Of 54 becoming lepromin-positive or doubtful, all became tuberculin-positive.

Of 64 becoming tuberculin-positive, 7 were previously leprominpositive, and, of the rest, 40 became lepromin-positive and I4 more became doubtful. Three cases becoming tuberculin-positive did not become lepromin-positive.

The tuberculin conversions were thus more numerous and definite than the lepromin conversions. All the lepromin conversions also showed tuberculin conversions; the tuberculin conversions did not always show a lepromin conversion.

These findings are in accord with the previously recorded findings of the two tests in healthy adults. While it is seen that tuberculin conversions are more numerous, there is evidence (35) that the lepromin conversions are more permanent. It also seems highly probable that the doubtful lepromin tests recorded after B.C.G. are significant.

\section{DOES A POSITIVE LEPROMIN TEST INDICATE IMMUNITY FROM LEPROSY?}

The general feeling of experienced leprologists is that it does.

A person who is found lepromin-positive, even after prolonged and intimate contact with leprosy, is practically always free from signs of leprosy, or else the disease is in the mild self-limiting form. 
Most workers believe that it is the power to react allergically to the leprosy bacillus, and the immunity which accompanies this phenomenon, which keep the person free from the disease, or, if the disease is acquired, keeps it in the mild form. It must be admitted that the proof of this idea is not complete. Moreover it may be that a positive lepromin test produced as a response to leprous infection might indicate immunity to leprosy, but one produced as a response to tuberculous infection or to B.C.G. might not be accompanied by and indicate the presence of immunity to leprosy. These matters are not easy to investigate, but more information is highly desirable.

The only available information bearing on this matter is contained in two reports, one by Fernandez (38) and one by Montestruc and Blaché (39).

Fernandez states " For several years I have had under observation a group of children who were inoculated with B.C.G. after birth and who have continued to live with their leprous parents. As yet, none of them has developed the lepromatous form." This statement would appear to imply that some have developed nonlepromatous forms of leprosy.

Montestruc and Blaché record a family in Martinique in which a lepromatous mother bore children in I938, I940 and I94I, and all three children were vaccinated with B.C.G. at birth, and revaccinated at $\mathrm{I}, 3,5$ and 9 years. All children have remained with the mother. In 1950 their ages were 12, I0, and 9 and they were healthy, and tuberculin- and lepromin-positive. Four other similar cases are reported in children (1950) aged I2, 9, 7 and 5. All were given B.C.G. at birth and two were revaccinated at one year. All have stayed with the mother and all are healthy. In four other similar children in similar circumstances but not given B.C.G., all have developed leprosy, at the ages of II months, 3, 5 and 7 years; three are lepromatous cases. Montestruc and Blaché realise that their numbers are small, but suggest that B.C.G. deserves a thorough trial in the prophylaxis of leprosy.

\section{CAN B.C.G. BE RECOMMENDED IN THE PROPHYLAXIS OF LEPROSY?}

Several experienced workers have already given their answer in the affirmative. Their answer is based on the experience already outlined. B.C.G. vaccine is now being widely recommended and used in the prophylaxis of leprosy, especially by French and South American workers, and in coming years much more evidence regarding its value may be produced. Until now, the evidence is meagre and much of it is indirect; arguments are based largely on experience of tuberculosis with the tuberculin test and B.C.G. 
But there are eminent tuberculosis workers who consider that the value of B.C.G. in the prophylaxis of tuberculosis is not proved, and a similar situation may be expected among leprosy workers.

Regarding B.C.G. and leprosy, one interesting and possibly vital question arises. I have already outlined the theory of certain experienced workers who postulate that there are a few persons who are inherently incapable of reacting allergically to the leprosy bacillus, and that these exposed to leprous infection become the progressive and infectious lepromatous cases. If this theory is true, and if the inability to react allergically to the leprosy bacillus is inherent and hereditary, then B.C.G. vaccination does not appear likely to overcome it. In other words it is possible that B.C.G. vaccine only " immunizes " those (the majority) who are already potentially allergic and potentially immune and do not need immunization, but fails to immunize those persons (the minority) who are inherently susceptible, and most need immunization.

We have studied four babies whose parents are both known to us as lepromatous cases under our own observation. All four babies were lepromin- and tuberculin-negative. After B.C.G., all four became tuberculin-positive and three lepromin-positive and one lepromin-doubtful. Other workers have reported similar findings to us, personally. It appears that any hypothetical inherent inability to react to lepromin is not acquired by direct heredity.

If all children of leprous parents even if both parents are lepromatous cases, can be rendered allergic to the leprosy bacillus by B.C.G., the case for the use of B.C.G. in prophylaxis will be considerably strengthened.

We have now reached the following position. A positive lepromin test is generally accepted as indicating some immunity to leprosy. A positive lepromin test is often produced by tuberculous infection as shown by the tuberculin test, and it can also be induced by B.C.G. vaccination. There is no clear indication that there are any persons who cannot be made lepromin-positive by B.C.G. vaccination, repeated and given orally if necessary (this can be done without ill effects, even if the tuberculin test is positive).

So far the position seems fairly clear.

But an important question arises. If tuberculosis immunizes against leprosy, might we not expect all cases of leprosy to be tuberculin-negative, indicating a lack of immunity conferred by previous tuberculous infection? The answer to this question is that while the mild self-limiting forms of leprosy showing immunity (positive lepromin test) might be expected to be tuberculin positive, the severe progressive cases showing no immunity (negative lepromin test) might be expected to show a negative tuberculin test. 
Is this expectation fulfilled? The answer is a very definite negative. Lepromin-negative (lepromatous) cases of leprosy show a tuberculin-positive rate little lower than that of the community from which they are drawn, and also as high as or higher than the tuberculoid leprosy cases in the same area. Moreover they frequently show tuberculous infection, and not infrequently die from it. The lepromatous case thus appears to disobey all the rules.

These findings refuse to be fitted into the picture we have been outlining. There are possible explanations or partial explanations. These lepromatous cases may have acquired serious leprosy before they became infected with tuberculosis, and by then it was impossible for the immunity induced by tuberculosis to manifest itself. There is some evidence that tends to confirm this view; for example in some countries it is recorded that lepromatous leprosy usually arises early in life, and that leprosy appearing later is more often mild; but in other countries this appears not to be so. It is doubtful if these ideas explain the anomalies.

It is impossible to discuss this matter fully here. A careful study of the lepromin test, the tuberculin test and B.C.G. vaccination in actual cases of leprosy has been made here and is reported later in this paper. It may however be said that the findings in lepromatous cases are very different from, and hardly reconcilable with, those of studies of healthy persons by the same methods here recorded. Our understanding of sensitivity and immunity in leprosy and tuberculosis is far from complete, and while cross-sensitivity is proved, and cross-immunity seems to be more than possible, there are some facts which cannot yet be reconciled with these ideas.

To return then to our question "Can B.C.G. be recommended in the prophylaxis of leprosy? " The evidence is incomplete and some of it appears contradicatory. There still remains doubt in the minds of some workers whether a positive lepromin test (particularly if induced by B.C.G.) really indicates immunity. Until such doubts can be resolved or confirmed, what is the reasonable attiude to adopt towards the question of B.C.G. immunization with a view of preventing leprosy?

It appears to us that its use, even at the present time, is justified, but that certain conditions should be fulfilled (a) It must not be used indiscriminately, but generally it should be confined to those healthy persons, mainly children, who are unavoidably exposed to leprous infection. (b) In countries where mass B.C.G. vaccination against tuberculosis is being adopted, it may be difficult so to confine its use. In such countries, an attempt should be made to utilize the mass B.C.G. campaign to give evidence of the value of 
B.C.G. in the prevention of leprosy. In some areas it may be possible for the B.C.G. campaign to be carried out by the leprosy staff, and to be designed specially to give evidence of its value in the control of leprosy. (c) All work with B.C.G. in countries with much leprosy should be planned, carried out and recorded in such a way that it can, in the future, give reliable evidence on the value of B.C.G. vaccination in the prevention of leprosy. (d) It should be made quite clear to every one concerned that B.C.G. vaccination of those exposed to infection does not remove the necessity for taking every possible step to prevent or minimize contact between open cases of leprosy and healthy persons, particularly children.

\section{B. STUDIES IN PERSONS WITH LEPROSY.}

Studies of the lepromin and tuberculin tests in cases of leprosy, and of the influence of B.C.G. immunization on the results of the tests in cases of leprosy, may be of interest. They might give some insight into the question of cross-immunity between the two diseases, and on the causation and significance of a positive lepromin reaction; they might give some indication whether B.C.G. immunization is likely to be of any value in the treatment of leprosy.

\section{Results in Cases of Leprosy.}

The results are here recorded in tabular form.

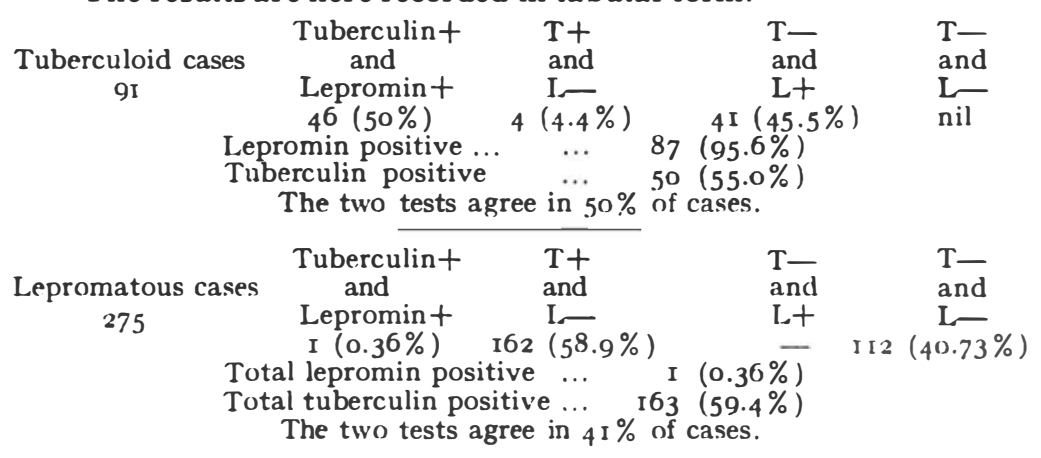

Discussion.

The literature on the tuberculin reaction in leprosy is very extensive, and it has been ably reviewed by Wade (40). He found that there were no major differences between the results recorded (a) in healthy persons in the area studied (b) in cases of tuberculoid type, and (c) in cases of lepromatous type. Some reports on work with purified antigens suggested that in lepromatous leprosy there was "evidence of a tendency to a lowered frequency of reaction."

We will first consider cases of tuberculoid type. This is the form 
of leprosy which is characterized by allergy to the leprosy bacillus and its products as demonstrated by the positive lepromin test. It is a relatively mild form of the disease, and is often sclf limiting. Histologically the lesions are of " tuberculoid " structure and closely resemble those of tuberculosis in its less acute forms, even in some cases to the extent of the production of caseation.

Early in this century, when what is now called the tuberculoid form of leprosy first attracted considerable attention, it was suggested that this form of leprosy was caused by leprous infection in a person who was also harbouring a tuberculous infection. More recent work already outlined has indicated (a) that this form of leprosy is associated with, and probably caused by, the power of the tissues of the infected person to react allergically to the infection, and (b) that tuberculous infection can sensitize the tissues in such a way as to enable them to react allergically to the leprosy bacillus. It thus appears that the old idea that in the aetiology of tuberculoid leprosy, both infections, leprosy and tuberculosis, may play a part, may contain a grain of truth, and that grain might possibly be quite large. Is it possible that tuberculoid leprosy really is the result of leprous infection in a person who was tuberculin-positive (and therefore usually lepromin-positive) before the leprous infection was acquired?

A study of the lepromin and tuberculin tests applied simultaneously in tuberculoid cases of leprosy should throw light on this subject. If tuberculoid leprosy were the result of leprous infection in a person harbouring and reacting allergically to a tuberculous infection, it would be reasonable to expect that all or nearly all tuberculoid leprosy cases will be not only lepromin-positive (which is so), but also tuberculin-positive. A study of our findings shows that this is not so. In fact the proportion of tuberculin-positives $(55.0 \%)$ is actually slightly lower than in lepromatous cases $(59.4 \%)$, and considerably lower than in healthy people in this area $(75.2 \%)$.

These findings go strongly against the idea that tuberculous infection is always a contributory factor in the causation of tuberculoid leprosy. This does not mean that it is never a contributing factor, although our findings give no clear indication on this point.

The other findings in tuberculoid cases call for little comment. As usual, practically all are found lepromin-positive; moreover a large number of strong positives is found in this group, larger than in healthy persons. The degree of positivity is related to the clinical manifestations of the active disease, past or present. In most of these patients when tested, the disease had been rendered inactive by chemotherapy, but the results of the lepromin test did not appear to be modified markedly. The inactive " major " tuberculoid cases 
still showed the strongest reaction, and the inactive " minor " ones a less strong but still definitely positive reaction.

The agreement between the lepromin tests and tuberculin tests is of a low order, agreement being seen in only $50 \%$ of cases, for large numbers of cases were lepromin-positive and tuberculinnegative.

The lepromatous form of leprosy, often severe, generalized and progressive, is characterized by anergy to the leprosy bacillus and its products as shown by the lepromin test. It might be (and probably has been) postulated that this anergy is due to the absence of tuberculous infection to make the person's tissues react allergically to the leprosy bacillus, and that the tuberculin-positive rate will therefore be low. A study of our findings shows that this is not so. In fact the tuberculin-positive rate $(59.4 \%)$ is higher than in tuberculoid cases $(55 \%)$, although not as high as in healthy persons $(75.2 \%)$.

It has been stated that in the lepromatous (anergic) form of leprosy, the reaction to tuberculin may be interfered with. On this point the evidence given by our studies is contradictory. On the one hand it is true that the lepromatous cases show a lower tuberculin-positive rate than the healthy persons studied. On the other hand they show a slightly higher rate than the tuberculoid cases. Our studies indicate that complete anergy to the leprosy bacillus (negative lepromin test) may be accompanied by a high degree of sensitization to tuberculin, even the cuti reaction being strongly positive.

As in tuberculoid leprosy, the two tests (lepromin and tuberculin) show agreement in a low proportion, (only $4 \mathrm{I} \%$ ), a high proportion being tuberculin-positive and lepromin-negative. These findings might be interpreted as indicating that tuberculous infection has no influence on the way a person's tissues react or fail to react to lepromin. This conclusion would not be justified by the evidence. It should be remembered that, although they predominate in this and other leprosy institutions, lepromatous cases form only a fraction of the total number of leprosy cases in the population (the size of the fraction varying widely in different countries between about $5 \%$ and $50 \%$.) Moreover the leprosy cases in countries where leprosy is prevalent form only a fraction of the total actually infected with leprosy, infections often proving abortive. It may be that the lepromatous cases represent that small fraction of the population in whom leprous infection itself, and also tuberculous infection, for some unknown reason completely fail to elicit an allergic response to the leprosy bacillus; some inherent factor necessary to produce this response may be lacking. This is the view 
of Rotberg and to some extent of Wade. Thus the fact that lepromatous (lepromin-negative) cases of leprosy may show a strongly positive tuberculin test must not be interpreted as indicating that in normal persons tuberculosis infection does not influence the result of the lepromin test. There are many indications that lepromatous cases are only that small fraction of the population which is immunologically abnormal in its reaction to the leprosy bacillus.

On the other hand it may be argued that in lepromatous cases with a positive tuberculin test, the lepromatous leprosy developed first, and the tuberculous infection was acquired later, too late for any allergy or immunity to leprosy to be established. This argument appears rather weak, but perhaps not impossibly so, and it is consistent with the finding often recorded that leprosy acquired early in life is more likely to appear in the lepromatous form than when acquired late in life, for early in life fewer persons have been infected with tuberculosis which may induce immunity to leprosy.

\section{The Results as a Whole.}

We will last consider the results as a whole. The nature of the forms of leprosy called " lepromatous " and " tuberculoid " make pointless any analysis by the methods used above in healthy persons, for lepromatous cases are nearly all lepromin-negative, and tuberculoid cases are nearly all lepromin-positive.

One point is striking; in both the lepromatous and the tuberculoid cases, the results of the two tests agree in only $50 \%$ or less of the cases.

Further the following data appear to be of interest.

Of 88 lepromin-positive cases, $47(53 \%)$ are tuberculin-positive while of 278 lepromin-negative cases, $166(59.7 \%)$ are tuberculin-positive.

Of 213 tuberculin-positive cases, $47(22.6 \%)$ are lepromin-positive while of $\mathrm{I} 53$ tuberculin negative cases $4 \mathrm{I}(26.6 \%)$ are lepromin-positive.

These findings, in cases of leprosy, give no evidence of any factor operating to make the results of the two tests agree; in fact the findings are consistent with the idea that the two tests are entirely independent. Thus the findings are in marked contrast with those made in healthy persons.

In lepromatous cases the characteristic anergy to the leprosy bacillus is often accompanied by allergy to tuberculin, so the fact that the two tests often give differing results is understandable. In tuberculoid cases, however, no such factor operates, and one would expect that agreement between the two tests would be as much as, 
or more than in healthy persons. This expectation is not fulfilled; and there is no obvious explanation.

\section{ConClusions.}

Studies of the tuberculin and lepromin tests in cases of leprosy, in marked contrast to similar studies in healthy persons, give no evidence of any cross-allergy and possible cross-immunity between the two infections.

\section{Results of B.C.G. Vaccination in Tuberculin-Negative CASES OF Leprosy.}

So far we have failed to trace any previous published report on this matter.

It seems possible that such a study might be of interest and practical value. In the first place it might give information on the immunology of leprosy. For example, if lepromatous cases are the result of an inherent inability to react allergically to the leprosy bacillus, and if this anergy is specific for the leprosy bacillus, the giving of B.C.G. in such cases should be expected to produce conversions from tuberculin-negative to tuberculin-positive, but not from lepromin-negative to lepromin-positive. If by any chance conversions from lepromin-negative to lepromin-positive were seen, it would be of interest to see what effect, if any, this would have on the leprosy.

In tuberculoid cases, already lepromin-positive, B.C.G. would be expected to produce conversion from tuberculin-negative to tuberculin-positive, but it would be of interest to see whether the already positive lepromin test was made more strongly positive, and whether there was any change in the leprous lesions which suggested a focal reaction.

It might be that B.C.G. has some value in improving the prognosis and the rapidity of response to treatment by inducing or increasing immunity to leprous infection.

I here summarise the data so far collected in our studies.

(a) Lepromatous Cases.

ro4 lepromatous cases, tuberculin-negative and lepromin-negative, were given one intradermal injection of o.I G of B.C.G., and the tuberculin and lepromin tests were repeated after two months.

Tuberculin tests.

Of 104 previous negative 88 showed a positive reaction Io showed a doubtful reaction

6 remained negative 
Lepromin tests.

Of I04 previous negative II became definitely positive

I9 showed a very slight late reaction

15 showed a slight early reaction only

59 showed no reaction whatever.

The Two Tests Together.

Of 88 becoming tuberculin-positive, 1o alsø became lepromin positive.

Of I6 not becoming tuberculin-positive, I became leprominpositive.

Of 25 becoming strongly tuberculin-positive (cuti), 7 also became lepromin positive.

Of 79 not becoming strongly tuberculin-positive (cuti), 4 became lepromin-positive.

Of II who became lepromin-positive, Io also became tuberculin-positive.

Of 93 who did not become lepromin-positive, 58 became tuberculin-positive.

\section{Conclusions.}

The definite tuberculin conversions were 88 out of I04, i.e., $84.6 \%$.

The definite lepromin conversions were II out of 104 ( $10.6 \%$ ), although there were another $34(32.7 \%)$ who showed slight reaction early or late but not enough to be classed as definitely positive.

In general, lepromin conversions were seen only in those who showed tuberculin conversions, and were seen mainly in those with the strongest tuberculin response.

These results show

(a) That lepromatous cases of leprosy show no appreciable inability to be made allergic to the tubercle bacillus by B.C.G.

(b) That lepromatous cases, while they are usually not made allergic to the leprosy bacillus by B.C.G., I0.6\% were and another $32.7 \%$ showed a slight tendency in that direction.

(c) The anergy of the lepromatous cases is specific for the leprosy bacillus; further it is not absolute, no less than $43.3 \%$ showing some reaction early or late, after B.C.G. 
(b) Tuberculoid Casis.

30 tuberculoid cases, all tuberculin-negative or doubtful, and 28 lepromin-positive, were vaccinated with B.C.G.

The results observed were:

Tuberculin tests.

Of 22 completely negative 17 became positive and 5 doubtful.

Of 8 previously doubtful 8 became positive.

Of $\overline{30} \quad \overline{25}$ became positive and $\overline{5}$ doubtful.

Lepromin tests.

(a) Early response to lepromin.

No response

Before B.C.G. After B.C.G.

Doubtful response

$4 \quad \mathrm{I}$

Definite response

13

I3 21

30 $\quad$ 30

(b) Late response.

Before B.C.G. After B.C.G.

$\begin{array}{rrr}\mathrm{I}+ & 2 & 2 \\ 2+ & 6 & 5 \\ 3+ & \mathrm{I} 3 & \mathrm{I} 2 \\ 4+ & 9 & \mathrm{II} \\ & - & - \\ & 30 & 30\end{array}$

Conclusions.

(a) The tuberculin conversions were normal.

(b) B.C.G. produced no marked increase in the late response to lepromin.

(c) B.C.G. produced a slight increase in the early response to lepromin.

Effect of B.C.G. Vaccination on the Disease.

Early effects on the disease.

No changes in the leprous lesions, or in the general condition of the patient, attributable to B.C.G. vaccination, were observed.

In lepromatous cases, " reaction" might have been expected, for such procedures as small-pox vaccination or TAB inoculation often produce it. The incidence of reaction in our lepromatous cases was not increased by B.C.G. This may have been because B.C.G. has no such effect, or it may be that since our patients had nearly all had prolonged chemotherapy with thiosemicarbazone or sulphone, the relative inactivity of the disease prevented this effect.

In tuberculoid cases, some focal reaction in the lesions might 
have been expected, for this is sometimes seen after the injection of lepromin or tuberculin. Such a focal reaction was seen in only one case, and that not very definite, but once again this may be because the infection had been or was being controlled by chemo. therapy.

\section{Late effects on the disease.}

It is the general opinion that those few lepromatous cases that naturally show a positive lepromin test have a better prognosis than the majority which do not. It is possible that the induction of a positive lepromin test by B.C.G. might improve the prognosis. We have so far made no observations which would confirm this idea, but the time since such B.C.G. vaccination has been very short.

Similar remarks may be made about the tuberculoid cases. We have as yet seen no beneficial effect of B.C.G. vaccine, but most of the lesions had previously been rendered inactive by chemotherapy.

SUMMARY.

The hypothesis that between tuberculosis and leprosy there exists a cross-immunity which may have an important bearing on the immunology, spread, prophylaxis, and epidemiology of leprosy is examined.

The nature of the lepromin test is discussed; a report is presented of the analysis of the results of simultaneous lepromin and tuberculin tests in 359 healthy persons in East Nigeria. The degree of agreement between the results of the two tests is found to be significant; the reason for the high degree of agreement is considered to be that tuberculous infection, as shown by the tuberculin test, makes people sensitive to lepromin as shown in the lepromin test.

The reports of other similar studies of the same subject by other workers in other countries are discussed and analysed in the same way, and give similar results.

The findings are presented of the study of the effect of B.C.G. vaccination on the lepromin and tuberculin tests in healthy persons. Of 65 persons previously tuberculin-negative, 64 were made tuberculin-positive. Of 58 of the same persons previously leprominnegative, 40 were made lepromin-positive and 14 were recorded as " doubtful." Lepromin conversions were seen only in persons who showed tuberculin conversions.

The question whether a positive lepromin test indicates immunity to leprosy is discussed, and the available evidence is presented; no definite conclusions are drawn, but the findings are considered suggestive.

The advisability of using B.C.G. vaccination of healthy people in prophylaxis in countries where leprosy is common is discussed. 
Its value is regarded as not proved, for the evidence is incomplete and some of it is contradictory. Nevertheless the view of Chaussinand " that B.C.G. vaccine deserves to be widely used in areas where leprosy is common and is difficult to control, and where the future extension of tuberculosis constitutes such a terrible menace' is endorsed, with the proviso that the work should be so planned and carried out that it affords evidence of the value or otherwise of B.C.G. vaccination in the control of leprosy and of tuberculosis, and that the use of B.C.G. shall not be regarded as rendering unnecessary the isolation of open cases from other persons, particularly children.

The findings are presented of a study of the lepromin and tuberculin tests in 366 cases of leprosy, 9I of tuberculoid type and 275 of lepromatous type.

The findings give no evidence to support the hypothesis that previous tuberculous infection renders leprosy mild because it produces some immunity to leprosy. Many tuberculoid cases were found tuberculin negative. Futher no evidence was afforded that in the absence of previous tuberculous infection, leprosy tended to be severe; most of the lepromatous cases were tuberculin-positive.

In general, the study of lepromin and tuberculin tests in cases of leprosy gave no evidence of cross-immunity between the two infections; this was in marked contrast to the studies in healthy persons. This contrast between studies in healthy persons and those in cases of leprosy is recorded; no attempt is made to explain it.

The effect of B.C.G. vaccination on the lepromin and tuberculin tests in 134 tuberculin-negative cases of leprosy has been studied.

The tuberculin conversions were about the same as in healthy persons, and were seen in both tuberculoid and lepromatous cases. The lepromin conversions (seen only in lepromatous cases for tuberculoid cases were already positive), were definite in 10\% and were slight in a further $32.7 \%$. These findings were unexpected, a lepromin-positive lepromatous case being usually regarded as hardly possible, and the term as being almost self-contradictory.

In tuberculoid cases (already lepromin positive), B.C.G. vaccination did not induce any marked increase in the response to lepromin; any increase seen was mainly in the early reaction and not in the late reaction.

B.C.G. vaccination did not produce any focal reaction in the leprous lesions. During the short period that has elapsed, there has not been any accelerated clinical improvement in the lepromatous cases that were rendered lepromin-positive. There is thus no definite indication so far that B.C.G. vaccine is likely to play any part in the treatment of leprosy. 
ACKNOWLFDGMENTS.

Thanks are due to Dr. R. Chaussinand and the Pasteur Institute, Paris for supplies of purified tuberculin and of lyophilized B.C.G.; to the staff and students of the Methodist College, Uzuakoli, and to the staff of the Leprosy Settlement, Uzuakoli, for volunteering to be the subjects of experimentation; to Dr. B. Nicholson of the Nigeria Leprosy Service for valuable help in the preparation of this paper and in dealing with the statistics; to the Leprosy Adviser to the Nigeria Government (Dr. T. F. Davey, O.B.E., M.Sc., M.D.) and to the Inspector General of Medical Services, Nigeria (Dr. S. L. A. Manuwa, C.M.G.), for permission to publish this paper.

\section{REFERENCES.}

1. Fernandez, J. M. M. (1939). Rev. Argent. de Dermato-Silfilol. 23, 425

2. Fernandez, J. M. M. (1943). Internat. Jour. Lep. II, 15.

3. Chaussinand, R. (1950) "La Lepre." Expansion Scientifique Française, Paris, p. 148, and (1948). Internat. Jour. Lep. 16, 431.

4. Hanks, J. H. (1945). Internat. Jour. Lep. 13, 25.

5. Hayashi, F. (1933). Internat. Jour. Lep. I, 31.

6. Mitsuda, K. (1916). Jap. Jour. Urol and Dermatol. quoted by Hayashi, F. Internat. Jour. Lep. I, 31.

7. MitsudA, K. (1924). Proceedings 3rd Int. Lep. Conf., Strasbourg 1924, Bailliere, Paris. 219.

8. BArgehr, P. (1926). Ztschr. f. Immunit. u. Exp. Therap. 47, 529.

9. Rotberg, A. (1937). Rev. brasiliera Leprol. 5, 45.

10. Fernandez, J. M. M. (1939). Ann. Paulista Med. c. Cir. 37, 308.

11. Fernandez, J. M. M. (1940). Internat. Jour. Lep. 8, 1.

12. Lowe, J. and Dharmendra (1941). Lep. in India 13, 81.

13. WADE, H. W. (1941). Internat. Jour. Lep. 9, 39.

14. WADE, H. W. (1950). Internat. Jour. Lep. 18, 487.

15. DhARMENDRA (1942). Lep in India 14, 122.

16. Dharmendra (1941). Lep. in India 13, 89.

17. Dharmendra and Jaikaria (1943). Lep. in India 15, 40.

18. Cummins, S. L., and Le Roux, J. J. DU PRe (1930). Tubercle II, 299.

19. Dharmendra and Jaikaria, S. S. (1941). Lep. in India, 13, 40.

20. Chaussinand, R. (1949). Rev. Colon. Med. Chir. 21, 170 (abstracted in Internat. Jour. Lep. 1950, p. 441).

21. Cummins, S. L., and Williams, E. M. (1934). Brit. Med. Jour. I, 702.

22. Dubois, A. (1936). Bull. Soc. Path. Exot. 29, 649.

23. Boncinelli, U. (1937). Gior. ital di dermatosif 23, 425.

24. Convit, J., Azulay, R. D., Bermudez, D., and Salgado, P. (1944). Internat. Jour. Lep. 12, 60.

25. Azulay, R. D., and Convit, J. (1947). Internat. Jour. Lep. 15, 264.

26. Bechelli, L., Keil, H., and Rotberg, A. (1945). Rev. brasiliera Leprol. 13, 21.

27. de Souza Campos, N., Rosemberg, J., and Aun, J. N. (1950). Rev. brasiliera Leprol. 17, 117. 
28. Garcia Miranda, A. (1946). Rev. Leprol. Dermat, y Sifl. Marianac, Cuba. 3, 120.

29. Rotberg, A., and Bechelli, L. M. (1948). Mem. V. Cong. Internat. Lepro. La Havana 1948-49. p. 586 reprinted in Internat. Jour. Lep. 18, 209.

30. Radna, R. (1938). Ann. Soc. belge. de Med. Trop. 18, 63.

31. Neyra Ramirez, J. (1951). Rev. San. Pol (Lima) II, 519.

32. Azulay, R. D. (1948). O. Hosp. (Rio de Janeiro) 34, 853.

33. Gines, A. and Poletti, J. (1946). Bol. Ofic. San. Panamericana 25, 884.

34. Rosemberg, J., de Souza Campos, N., and Aun. J. N. (1950). Rev. brasiliera Leprol. 18, 3.

35. Rosemberg, J., de Souza Campos, N., and Aun, J. N. (1950). Rev. brasiliera Leprol. 18, 128.

36. Rudianski, E. (1948). Rev. brasiliera Leprol. 17, 27.

37. Dauden Valls, F., Mora Comas, J. y Dauden Salas (1951). Actas Dermosif. 42, 505.

38. Fernandez, J. M. M. (1951). Internat. Jour. Lep. 19, 474.

39. Montestruc, E., and Blache, R. (1950). Rev. Colon. .Med. Chirur. 15, 358.

40. WADE, H. W. (1950). Internat. Jour. Lep. 18, 373. 